\title{
Conscious sedation with dexmedetomidine compared with asleep-awake-asleep craniotomies in glioma surgery: an analysis of 180 patients
}

\author{
*Eric Suero Molina, MD, MBA, ${ }^{1}$ Stephanie Schipmann, MD," Isabelle Mueller, ${ }^{1}$ \\ Johannes Wölfer, MD, ${ }^{1}$ Christian Ewelt, MD, ${ }^{1}$ Matthias Maas, MD, ${ }^{2}$ Benjamin Brokinkel, MD, ${ }^{1}$ \\ and Walter Stummer, MD1
}

\begin{abstract}
${ }^{1}$ Department of Neurosurgery, and ${ }^{2}$ Department of Anaesthesiology, Intensive Care and Pain Therapy, University Hospital of Münster, Germany
\end{abstract}

\begin{abstract}
OBJECTIVE Awake craniotomies have become a feasible tool over time to treat brain tumors located in eloquent regions. Different techniques have been applied in neurooncology centers. Both "asleep-awake-asleep" (asleep) and "conscious sedation" were used subsequently at the authors' neurosurgical department. Since 2013 , the authors have only performed conscious sedation surgeries, predominantly using the $\alpha 2$-receptor agonist dexmedetomidine as the anesthetic drug. The aim of this study was to compare both mentioned techniques and evaluate the clinical use of dexmedetomidine in the setting of awake craniotomies for glioma surgery.
\end{abstract}

METHODS The authors retrospectively analyzed patients who underwent operations either under the asleep condition using propofol-remifentanil or under conscious sedation conditions using dexmedetomidine infusions. In the asleep group patients were intubated with a laryngeal mask and extubated for the assessment period. Adverse events, as well as applied drugs with doses and frequency of usage, were recorded.

RESULTS From 224 awake surgeries between 2009 and 2015, 180 were performed for the resection of gliomas and included in the study. In the conscious sedation group $(n=75)$ significantly fewer opiates $(p<0.001)$ and vasoactive $(p$ $<0.001)$ and antihypertensive $(p<0.001)$ drugs were used in comparison with the asleep group $(n=105)$. Furthermore, the postoperative length of stay $(p<0.001)$ and the surgical duration $(p<0.001)$ were significantly lower in the conscious sedation group.

CONCLUSIONS Use of dexmedetomidine creates excellent conditions for awake surgeries. It sedates moderately and acts as an anxiolytic. Thus, after ceasing infusion it enables quick and reliable clinical neurological assessment of patients. This might lead to reducing the amount of administered antihypertensive and vasoactive drugs as well as the length of hospitalization, while likely ensuring more rapid surgery.

https://thejns.org/doi/abs/10.3171/2017.7.JNS171312

KEY WORDS awake craniotomy; glioma; dexmedetomidine; surgical technique; sedation

$\mathrm{B}$ RAIN tumors located near eloquent regions represent a surgical challenge when pursuing a good functional outcome after resection. For more than a century, awake craniotomies have been part of the treatment of tumors and other pathologies located in eloquent regions. Victor Horsley was one of the first surgeons to stimulate the brain cortex during epilepsy surgery under local anesthesia in $1887 .{ }^{17}$ Conscious sedation has helped surgeons assess important neurological functions while preserving functional integrity when performing resection of tumor tissue in critical anatomical regions. ${ }^{4,8,36,37}$ Awake craniotomies have been shown to extend intracranial tumor resection while keeping the patient safe. ${ }^{8-10,30}$ However, finding the optimal balance between dosage and type of sedative, analgesic, and anxiolytic drugs and keeping the patient clinically and neurologically assessable without cardiorespiratory compromise remains challenging.

Different techniques have been applied in neurosur-

ABBREVIATIONS $A A=$ anaplastic astrocytoma; $A S A=$ American Society of Anesthesiologists $; \mathrm{Cl}=$ confidence interval; $\mathrm{MAP}=$ mean arterial pressure SUBMITTED May 28, 2017. ACCEPTED July 14, 2017.

* Drs. Suero Molina and Schipmann contributed equally to this work. 
gical and neurooncological centers: an "asleep-awakeasleep" (asleep) setting, which involves general anesthesia before and after the testing phase; monitored anesthesia care or "conscious sedation" setting, in which patients are mildly sedated but respiratory independent during the complete procedure; as well as an "awake-awakeawake" setting. All of these have been discussed in the literature. ${ }^{15,16,24,31,32,35}$ The first two of these techniques have previously been applied at the Department of Neurosurgery, University Hospital of Münster. Given recent publications, we decided to maintain the nomenclature "conscious sedation." ${ }^{23,35}$ Since 2013, the department has solely been performing conscious sedation surgeries using the $\alpha 2$-receptor agonist dexmedetomidine as the only anesthetic drug. Dexmedetomidine acts as a sedative and induces amnesia and analgesia. Moreover, it has an anxiolytic effect, which plays an essential role for its efficacy during awake craniotomies. ${ }^{14}$ The aim of this study was to compare both techniques and evaluate the clinical impact of dexmedetomidine in the setting of awake craniotomies for glioma surgery.

\section{Methods \\ Study Population}

We performed an exploratory single-center post hoc analysis of consecutive patients who underwent surgery for intracranial neoplasms under awake conditions at the Department of Neurosurgery of the University Hospital of Münster from October 2009 to September 2015. The setting was either "asleep" using propofol-remifentanil sedation or "conscious sedation" using only dexmedetomidine infusions. As of 2013, the department changed regimens and exclusively performed the conscious sedation procedure. Data collection and scientific analysis in this retrospective cohort study were approved by the local ethics committee of the University of Münster. Written informed consent was obtained for allowing analysis of tumor tissue and clinical data of patients for scientific purposes.

\section{Data Collection}

Clinical data, such as electronic medical records, surgical reports, and digitized anesthesia protocols, were evaluated for each patient (Table 1). Adverse events as well as the drug doses and frequency of usage were recorded. Patient compliance during intraoperative monitoring was evaluated according to the surgeons' perception. Patient compliance was ranked using a subjective rating scale from 1 to 6 (similar to the German school grading system), with 1 representing the best grade, based on the overall impression regarding the criteria of orientation, alertness, capability of articulating clearly, and time until useful mapping/monitoring was possible.

\section{Surgical Procedures}

In the asleep group patients were sedated with propofol and remifentanil, and fitted with a laryngeal mask in the anesthetic ward, which was removed for the assessment period during surgery. No standard premedication was administered. Patients in the conscious sedation group were sedated with dexmedetomidine $(0.5-1.6 \mu \mathrm{g} / \mathrm{kg}$ body weight $/ \mathrm{hr}$ ) outside of the assessment phase. Patients in the conscious sedation group were positioned in the Mayfield clamp (Integra LifeSciences) under local anesthesia while conscious, and repeatedly questioned about the comfort of their position before sedation was deepened for craniotomy.

In a number of cases, remifentanil was added with a low dose of maximal $0.05 \mu \mathrm{g} / \mathrm{kg}$ body weight per minute. Capnography was applied to monitor spontaneous ventilation. No premedication was given in these cases. A scalp block with $0.5 \%$ ropivacaine and 1:200,000 (5 $\mu \mathrm{g} / \mathrm{ml})$ epinephrine was used in both settings. Furthermore, the pin sites and the incision line were carefully infiltrated with ropivacaine and epinephrine.

Patients were positioned either lateral or supine. Standard neuronavigation was used for planning craniotomies (BrainLAB). We used transparent drapes (Secu-Drape, STS Medical Group) to enable close monitoring of the patients' performance during mapping and monitoring.

During craniotomy, patients were asked to open their mouths to avoid excessive noise exposure. However, due to the sedative effect of dexmedetomidine, this was not necessary in most of the cases, because patients were sufficiently sedated. For resection, tumor extension was delineated primarily using ultrasonography (Aloka, Hitachi Medical Systems), and Gliolan (Medac) in suspected high-grade glioma, and secondarily by the use of neuronavigation. For mapping, stimulation was performed with a 50-Hz bipolar Ojemann-type stimulator (ISIS, inomed). Initial intensity was regularly low $(1 \mathrm{~mA})$ and slowly increased if necessary for determining the patient's individual stimulation threshold. Care was taken to expose the motor cortex to elicit motor responses from stimulation, if possible. Continuous stimulation time was maximally 3 seconds and a single area was not stimulated more than 3 times in succession. Proximity to eloquent regions and the intensity of the stimulation marked the threshold for evoking a response. Iced Ringer's lactate solution was always available for seizure suppression. ${ }^{28}$

\section{Neurological Assessment}

Neurological assessment techniques differed according to the anatomical region of surgery. Normally, for speech assessment, a tablet computer with a set of different images was used for object-naming or verb-generation exercises. Other paradigms included counting, reading, monitoring of visual fields, spatial perception, and mathematics. Motor assessment was performed by a neurosurgical resident known to the patient, and the assessment of neurocognitive functions performed by a neurophysiologist.

\section{Statistical Analysis}

Descriptive statistics were used to evaluate patient populations. Statistical analyses were performed using the commercially available statistical software SPSS (version 23.0, IBM Corp.). Significance was defined as the probability of a 2 -sided type 1 error of $<5 \%$ ( $p<0.05)$. To compare both study groups, univariate test analysis for quantitative factors and chi-square tests or the Fisher's exact test for categorical variables were applied. Age-, sex-, 
American Society of Anesthesiologists (ASA) score-adjusted multivariate analyses were performed using logistic regression and characterized by $95 \%$ confidence intervals (CI) and $p$ values for each significant variable after univariate analysis.

\section{Results}

Two hundred twenty-four awake surgeries were performed by senior neurosurgeons from October 2009 to September 2015 in the Department of Neurosurgery at the University Hospital of Münster. One hundred eighty surgeries were performed for the resection of gliomas and included in this study. We excluded the other patients to analyze a mainly homogenous population. Other procedures were performed for vascular surgery (arteriovenous malformation, cavernoma) or for surgery of metastases.

In the asleep group $(\mathrm{n}=105), 41$ patients $(39 \%)$ were female. The mean patient age was 48.21 years (range 16-78 years; Table 1). Neuropathological findings of intraoperatively acquired tissue demonstrated 32 astrocytomas (WHO grade II, 30.5\%), 21 anaplastic astrocytomas (AAs, WHO grade III, 20\%), and 52 glioblastomas (WHO grade IV, $49.5 \%)$, with 69 patients $(65.7 \%)$ undergoing operations for the first manifestation of the disease. The other $36 \mathrm{pa}-$ tients were experiencing first $(\mathrm{n}=29,27.6 \%)$ and second $(\mathrm{n}=7,6.7 \%)$ recurrences.

In the conscious sedation group $(n=75)$ the male/ female ratio was 52/23 with a mean age of 50.89 years (range 19-81 years; Table 1). After histopathological examination, 21 astrocytomas (28\%), 13 AAs (17.3\%), and 41 glioblastomas $(54.7 \%)$ were diagnosed. Forty-five patients $(60 \%)$ had their first manifestation of the disease, whereas in this group first $(\mathrm{n}=24,32 \%)$, second $(\mathrm{n}=5,6.7 \%)$ and even third $(\mathrm{n}=1,1.3 \%)$ recurrences were operated on as well. There was no statistically significant difference in sex $(p=0.247)$ or age $(p=0.238)$ between groups (Table $1)$.

\section{Blood Pressure and Heart Rate}

There was a significantly longer hypertension perioddefined as more than $20 \%$ of the mean arterial pressure (MAP) measured before anesthesia induction-in the asleep group, with a mean duration of 31.96 minutes (median 25 minutes, range 5-115 minutes), compared with the conscious sedation group $(\mathrm{p}<0.001)$, in which the mean duration of hypertension was 25.67 minutes (median 5 minutes, range 5-350 minutes). In the same manner, hypotension phases, defined as less than $20 \%$ of the MAP before anesthesia induction, were slightly longer in the asleep group (median 65 minutes, range 5-635 minutes) than the conscious sedation group (median 102.5 minutes, range 5-305 minutes), but not significantly different.

Patients suffered from tachycardia (> $100 \mathrm{bpm})$ in the asleep group (mean 41.4 minutes, median 22.5 minutes, range 1-370 minutes) at a frequency similar to that of the conscious sedation group (mean 37.69 minutes, median 15 minutes, range 5-235 minutes; nonsignificant difference). In the same manner, bradycardia $(<60 \mathrm{bpm})$ was similar in both the asleep group (mean 135.7 minutes, median 90 minutes, range 5-585 minutes) and in the conscious se-
TABLE 1. Univariate analysis of demographics of the patient population

\begin{tabular}{|c|c|c|}
\hline Variable & Asleep & $\begin{array}{l}\text { Conscious } \\
\text { Sedation }\end{array}$ \\
\hline No. of patients & 105 & 75 \\
\hline \multicolumn{3}{|l|}{ Sex, $n(\%)$} \\
\hline Male & $64(60.9)$ & $52(69.3)$ \\
\hline Female & $41(39)$ & $23(30.7)$ \\
\hline Mean age in yrs (range) & $48.21(16-78)$ & $50.89(19-81)$ \\
\hline \multicolumn{3}{|l|}{ Diagnosis, $\mathrm{n}(\%)$} \\
\hline Astrocytoma, WHO grade II & $32(30.5)$ & $21(28)$ \\
\hline AA, WHO grade III & $21(20)$ & $13(17.3)$ \\
\hline Glioblastoma, WHO grade IV & $52(49.5)$ & $41(54.7)$ \\
\hline \multicolumn{3}{|l|}{ Recurrence status, $\mathrm{n}(\%)$} \\
\hline First disease & $69(65.7)$ & $45(60)$ \\
\hline First recurrence & $29(27.6)$ & $24(32)$ \\
\hline Second recurrence & $7(6.7)$ & $5(6.7)$ \\
\hline Third recurrence & & $1(1.3)$ \\
\hline \multicolumn{3}{|l|}{ Comorbidities, $\mathrm{n}(\%)$} \\
\hline Other malignant tumors & $1(0.9)$ & $2(2.7)$ \\
\hline Arterial hypertension & $10(9.5)$ & $9(12.0)$ \\
\hline Cardiac & $5(4.8)$ & $2(2.7)$ \\
\hline Respiratory & $4(3.8)$ & $4(5.3)$ \\
\hline Psychiatric & $1(0.9)$ & $3(4)$ \\
\hline Diabetes mellitus & $2(1.9)$ & $3(4)$ \\
\hline None & $71(67.6)$ & $46(61.3)$ \\
\hline \multicolumn{3}{|l|}{ ASA score, $n(\%)$} \\
\hline 1 & $18(17.1)$ & $17(26.6)$ \\
\hline 2 & $68(64.8)$ & $33(51.6)$ \\
\hline 3 & $14(13.3)$ & $14(21.8)$ \\
\hline Mean BMl in $\mathrm{kg} / \mathrm{m}^{2}$ (range) & $26.54(19.9-42.9)$ & $25.97(19.4-37.2)$ \\
\hline \multicolumn{3}{|l|}{ Tumor localization, n (\%) } \\
\hline Frontal lobe & $60(57.1)$ & $35(46.7)$ \\
\hline Temporal lobe & $25(23.8)$ & $23(30.7)$ \\
\hline Occipital lobe & $2(1.9)$ & $1(1.3)$ \\
\hline Parietal lobe & $16(15.2)$ & $15(20)$ \\
\hline Insular cortex & $2(1.9)$ & $1(1.3)$ \\
\hline
\end{tabular}

dation group (mean 115.65 minutes, median 75 minutes, range 5-555 minutes; nonsignificant difference).

\section{Seizures and Compliance}

From all patients in the asleep group, $9(8.5 \%)$ suffered general $(n=5,4.8 \%)$ or focal $(n=4,3.8 \%)$ seizures intraoperatively. In the conscious sedation group, 7 patients (9.3\%) experienced general seizures and $6(8 \%$, nonsignificant) experienced focal seizures (Table 2).

Overall compliance from the surgeon's perspective was reported to be similar in the asleep group (mean ranking 2.42 , median 2) as in the conscious sedation group (mean ranking 2.2, median 2; nonsignificant difference). However, in the asleep group there were a significantly higher number of cases in which monitoring needed to be terminated $(\mathrm{n}=22[21 \%]$ vs $\mathrm{n}=5[6.7 \%], \mathrm{p}<0.008)$, with lack 
TABLE 2. Patient operative characteristics and adverse events of the study cohort

\begin{tabular}{lccc}
\hline \multicolumn{1}{c}{$\begin{array}{c}\text { Operative Characteristicl } \\
\text { Adverse Event }\end{array}$} & Asleep & $\begin{array}{c}\text { Conscious } \\
\text { Sedation }\end{array}$ & $\begin{array}{c}p \\
\text { Value }\end{array}$ \\
\hline Respiratory insufficiency & $2(1.9)$ & $2(2.7)$ & NS \\
\hline Nausea & $7(6.7)$ & $2(2.7)$ & NS \\
\hline Seizures & & & NS \\
$\quad$ General & $5(4.8)$ & $7(9.3)$ & \\
Focal & $4(3.8)$ & $6(8.0)$ & \\
One & $96(91.4)$ & $62(82.7)$ & \\
\hline Termination of monitoring & $22(21)$ & $5(6.7)$ & 0.008 \\
Lack of compliance & $14(13.3)$ & $2(2.7)$ & \\
Anesthesiological complications & $3(2.8)$ & $1(1.3)$ & \\
Seizures & $1(0.9)$ & $1(1.3)$ & NS \\
Pain & $4(3.8)$ & $1(1.3)$ & \\
Patient's wish & & $1(1.3)$ & \\
\hline Mean compliance ranking (1-6) & 2.4 & 2.2 & NS \\
\hline Conversion to endotracheal intubation & $2(1.9)$ & $1(1.3)$ & NS \\
Seizures & $1(0.9)$ & & \\
Anesthetic complications & $1(0.9)$ & & NS \\
Patient's wish & & $1(1.3)$ & \\
\hline
\end{tabular}

NS = nonsignificant.

Pain, nausea, seizures, compliance ranking, and respiratory insufficiency, even if nominally higher, were not statistically significantly higher in the asleep group. However, significantly more patients required a termination of monitoring $(p=0.008)$, predominantly because of lack of compliance. All data given as number of patients (\%) unless otherwise indicated. Boldface type indicates statistical significance.

of compliance being the major reason $(n=14$ [13.3\%] vs $\mathrm{n}=2[2.7 \%])$. Other reasons for lack of compliance were anesthesiological complications $(n=3[2.8 \%]$ vs $n=1$ $[1.3 \%])$, seizures $(n=1[0.9 \%]$ vs $n=1[1.3 \%])$, pain, and the patients' request (Table 2).

\section{Pain, Antihypertensive, and Vasopressor Drugs}

In the conscious sedation group significantly fewer opiates $(\mathrm{p}<0.001)$ and vasoactive (e.g., noradrenaline: mean 2.13 vs $0.311 \mathrm{mg}, \mathrm{p}<0.001$ ) and antihypertensive drugs (e.g., urapidil: 111.01 vs $43.41 \mathrm{mg}, \mathrm{p}<0.001$ ) were used in comparison with the asleep group (Table 3). Furthermore, nonopioid analgesics were similarly needed in both groups (mean 1.1 vs $0.93 \mathrm{~g}$, nonsignificant difference). However, the administration of nonopioid analgesics is standard in our clinic after craniotomies.

\section{Steroids and Antiemetic Drugs}

As for steroids (dexamethasone), there was no significant difference between groups and the steroids administered, because patients receive $8 \mathrm{mg}$ of dexamethasone before the beginning of surgery, which is standard in our clinic. Furthermore, we found no significant differences between cohorts regarding the use of antiemetic drugs.

\section{Fluid Administration}

Fluid resuscitation was performed predominantly with crystalloids. Colloids and mannitol were also administered. However, mannitol was given for its osmotic effect, and not for fluid resuscitation. The conscious sedation group received significantly fewer crystalloids and colloids during surgery $(\mathrm{p}<0.001$; Table 3$)$.

\section{Length of Stay and Duration of Surgery}

The overall length of stay (mean 7 vs 5 days, $p<0.001$ ) and the overall duration of surgery, i.e., from anesthesia induction until the patient is awake and transferred from the operative room (mean 377.68 vs 321.43 minutes, $\mathrm{p}<$ 0.001 ), were significantly lower in the conscious sedation group (Fig. 1). The duration of surgery was defined as the time from anesthesia induction until the final minute in the recovery room before being transferred to the intensive care unit. After dividing the overall surgical time into single steps and comparing them, incision to suture time (mean 252.45 vs 202.32 minutes, $\mathrm{p}<0.001$ ) and the awakening time (mean 22.63 vs 15.45 minutes, $\mathrm{p}<0.001$ ) were significantly shorter in the conscious sedation group (Fig. 1 lower).

\section{Multivariate Analysis}

Multivariate analysis confirmed a significantly shorter postoperative length of stay in the conscious sedation group ( $\mathrm{p}=0.015,95 \%$ CI $0.277-2.596)$, as well as incision

TABLE 3. Univariate and multivariate analysis of drug use and fluid administration between the two groups

\begin{tabular}{|c|c|c|c|c|c|}
\hline \multirow[b]{2}{*}{ Drug } & \multirow[b]{2}{*}{ Asleep } & \multirow{2}{*}{$\begin{array}{l}\text { Conscious } \\
\text { Sedation }\end{array}$} & \multirow{2}{*}{$\begin{array}{c}\text { Univariate Analysis, } \\
\text { p Value }\end{array}$} & \multicolumn{2}{|c|}{ Multivariate Analysis } \\
\hline & & & & $95 \% \mathrm{Cl}$ & $p$ Value \\
\hline Opiates (mg) & 1426.79 & 157.87 & $<0.001$ & $109.11-1717.29$ & 0.027 \\
\hline Noradrenaline (mg) & 2.13 & 0.311 & $<0.001$ & -16.47 to 207.01 & 0.094 \\
\hline Urapidil (mg) & 111.01 & 43.41 & $<0.001$ & $44.57-129.42$ & $<0.001$ \\
\hline Dihydralazine (mg) & 1.83 & 0 & $<0.001$ & -1.3 to 5.32 & 0.235 \\
\hline Metoprolol (mg) & 8.32 & 0.253 & $<0.001$ & $6.35-10.67$ & $<0.001$ \\
\hline Crystalloids (ml) & 2863.64 & 2321.92 & $<0.001$ & $180.39-852.53$ & 0.003 \\
\hline Colloids (ml) & 593.18 & 22.27 & $<0.001$ & $388.75-682.73$ & $<0.001$ \\
\hline
\end{tabular}

Mean values demonstrating that patients in the conscious sedation group $(n=75)$ received fewer opiates $(p<0.001)$ and vasoactive $(p<$ $0.001)$ and antihypertensive $(p<0.001)$ drugs in the univariate analysis than patients in the asleep group $(n=105)$. Furthermore, patients in the conscious sedation group required less fluid administration during surgery $(p<0.001)$. All of these statistically significant results were confirmed in the multivariate analyses, with the exception of usage of the vasoactive drug noradrenaline and antihypertensive drug dihydralazine. 


\section{Postoperative length of stay (days)}

"Conscious sedation"

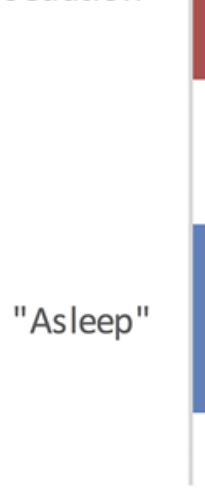

0
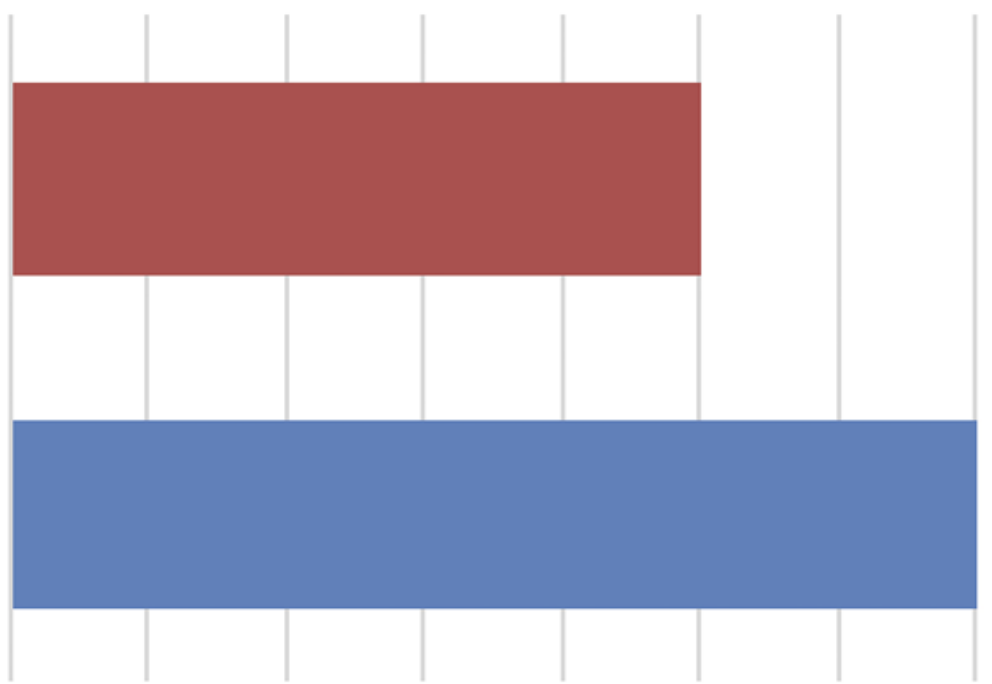

3

4

5

6

7

8

\section{Length of surgery}

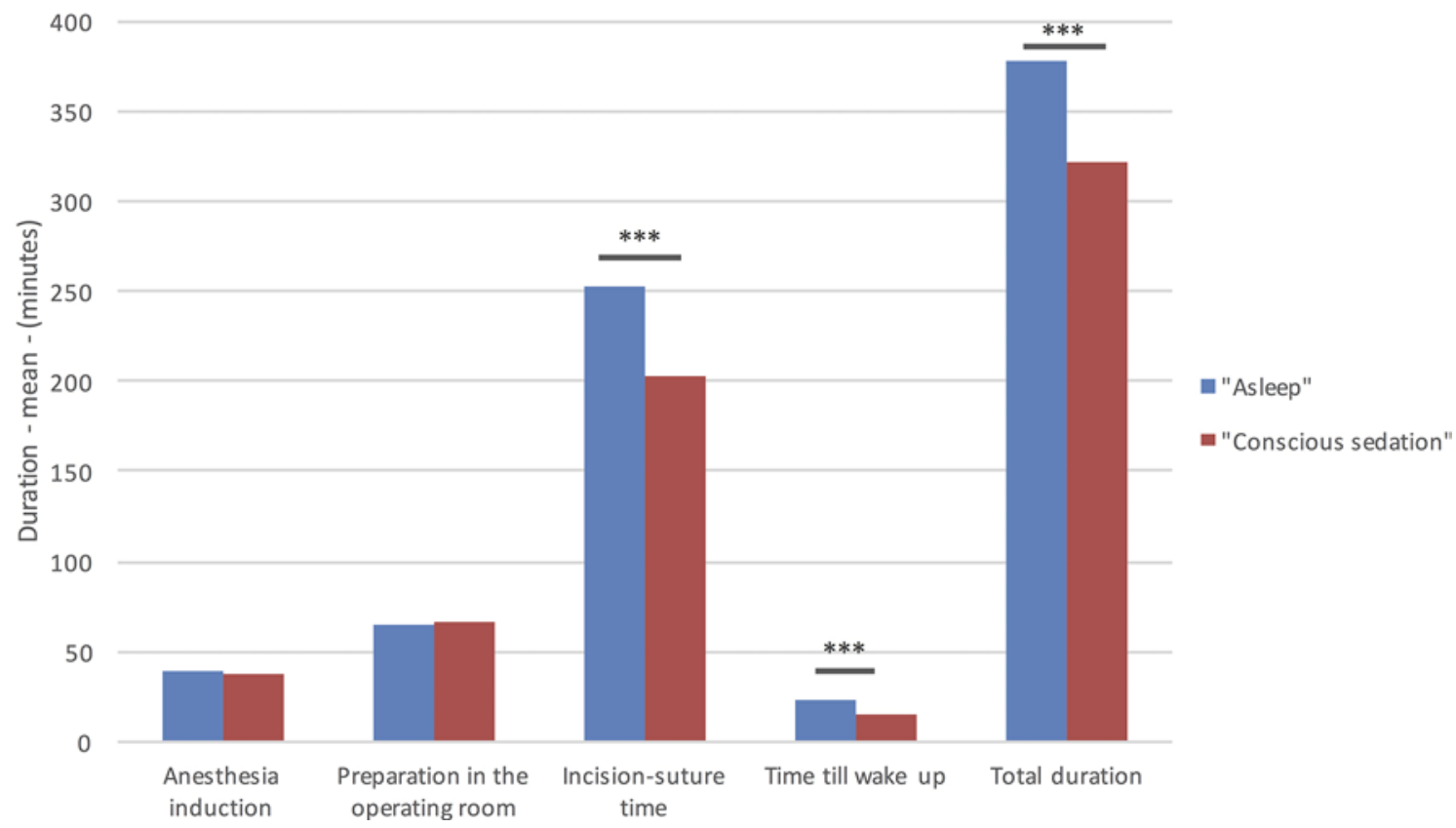

FIG. 1. Graphs showing statistically significantly shorter ( $\left.{ }^{* * *} p<0.001\right)$ mean postoperative length of stay (7 vs 5 days; upper); incision suture time ( 252.45 vs 202.32 minutes; lower), awakening time (22.63 vs 15.45 minutes; lower), and total duration of surgery (377.68 vs 321.73 minutes; lower) in the conscious sedation group $(n=75)$. Figure is available in color online only.

to suture time ( $\mathrm{p}<0.001,95 \%$ CI $29.59-72.37)$, awakening time $(\mathrm{p}=0.049,95 \%$ CI $0.42-14.21)$, and overall surgical duration ( $\mathrm{p}<0.001,95 \%$ CI 28.89-82.96). Additionally, except for the vasoactive drug noradrenaline and the antihypertensive drug dihydralazine, drugs and fluid administration were likewise statistically significant (Table 3). Furthermore, multivariate analysis for termination of monitoring did not show any correlation with comorbidi- ties, age, sex, ASA score, tumor location, or diagnosis. However, compliance rating was significantly associated with termination of monitoring $(\mathrm{p}=0.003)$.

\section{Discussion}

In this study we report on 180 patients with glioma who underwent operations under awake conditions. Awake 
craniotomy has enabled gross-total resection of tumors within or next to highly eloquent regions, improving their medical management, while making microsurgery feasible. ${ }^{26,27,35}$ Real-time patient feedback is crucial when aiming to achieve gross-total resection of these malignancies. Awake craniotomies represent a challenge for the anesthesiologist and the surgeon, especially due to possible pain and anxiety of the patient, and possible risks from seizures, vomiting, and aspiration. From our point of view, interdisciplinary work with anesthesiology and neurosurgical expertise is essential for good outcomes when performing awake craniotomies.

Dexmedetomidine's distinct pharmacological effects are ideal for use during awake craniotomies. As a highly selective $\alpha 2$-receptor agonist, dexmedetomidine acts as an anxiolytic, mild sedative, and analgesic. With the correct dosage, dexmedetomidine rarely induces cardiorespiratory suppression. ${ }^{2,3,14,38}$ Several studies described a combination of dexmedetomidine with remifentanil, propofol, nitrous oxide, and sevoflurane or fentanyl..$^{1,74}$ Conscious sedation with dexmedetomidine has been reported to be suitable for high-risk patients with difficult airway management, being associated with a generally low necessity for performing active rescue airway management. ${ }^{12}$ In a recent study, dexmedetomidine demonstrated significantly fewer adverse respiratory events compared with sedation with propofol and remifentanil. ${ }^{13}$ Dexmedetomidine appears to induce no respiratory suppression by itself but rather in combination with other drugs. ${ }^{13,25}$ In a previous report, dexmedetomidine was even used in a pediatric patient for an awake craniotomy, providing adequate sedation. ${ }^{33}$

Regional anesthesia of the scalp was performed in both settings as previously described. ${ }^{21}$ Local anesthesia involved injection of a mixture of ropivacaine and epinephrine, as described above. We experienced no adverse events regarding the local anesthesia injection.

Our experience demonstrated that in the asleep setting, patients require a longer time before intraoperative monitoring can reliably be performed, mostly due to a period of confusion after terminating the administration of anesthetics. In our cohort, compliance was nominally rated as superior in the conscious sedation group. A previous report demonstrated that failure of awake surgery leads to lower rates of gross-total resection and longer hospitalization times. ${ }^{19}$ In the present study, lack of compliance was the major reason for the termination of monitoring $(\mathrm{n}=$ $14,13.3 \%$ [asleep] vs $\mathrm{n}=2,2.6 \%$ [conscious sedation]). Furthermore, overall duration of surgery (median 377.68 vs 321.73 minutes, $p<0.001$ ) and postoperative length of hospital stay were significantly shorter in the conscious sedation group (mean 7 vs 5 days, $p<0.001$ ). Both of these variables have been positively correlated with surgical site infections and have been established as quality indicators for outcome assessment, ${ }^{29}$ not to mention the costs saved by significantly reducing surgery and hospitalization time. We are aware, however, that there has been a trend over time to discharge patients earlier.

One challenge during awake craniotomies is alternating between the individual phases of surgery. In our hands, the monitoring phase is not always performed in one single step. In some cases, longer interruptions of monitoring might require anesthesiologists to resume sedation to enable patient compliance for a later stage of the operation. On the other hand, it has been questioned whether dexmedetomidine as a single anesthetic drug provides sufficient analgesia and anesthesia, especially during the opening part of surgery. ${ }^{13,18,22}$ This was not reflected by our experience. For these reasons, however, we added low-dose remifentanil to our sedation regimen in some cases.

From the total number of patients in this study $(\mathrm{n}=180)$, $22(12.2 \%)$ experienced intraoperative seizures, a lower rate than previously reported..$^{20}$ We did not find a significant difference between study groups, with 9 individuals (8.5\%) in the asleep group compared with 13 (17.3\%, nonsignificant) in the conscious sedation group experiencing intraoperative seizures, even though propofol is known to have an anticonvulsant effect. ${ }^{5}$

On the other hand, patients in the asleep group received significantly more opiates than those in the conscious sedation group ( $p<0.001)$ as part of the standard regimen. The amount of nonopiate analgesics required by patients was nominally higher in the asleep group, without reaching statistical significance. In the same manner, nominally more patients in the asleep group $(n=4[3.8 \%]$ vs $n=1$ [1.3\%]) complained of pain during surgery. This implies that patients under conscious sedation with dexmedetomidine do not suffer more pain during awake craniotomy than under sedation with propofol and remifentanil.

There is no doubt that a surgical setting that requires significantly fewer vasoactive and antihypertensive drugs is better for the patient. Dexmedetomidine leads to fewer cardiovascular adverse effects during surgery. Patients sedated with dexmedetomidine experienced significantly fewer hypertensive periods. Furthermore, patients appeared to suffer fewer bradycardia and tachycardia incidents during surgery, without these differences reaching statistical significance. Even though hypotension and bradycardia have been reported as the most common cardiovascular effects of dexmedetomidine, ${ }^{6,11}$ we could not determine any such reactions, or to be more precise, we did not find hypotension and bradycardia in patients treated with dexmedetomidine to be more common compared with patients under the asleep-awake-asleep setting. Consequently, fluid resuscitation was significantly lower in the conscious sedation group $(\mathrm{p}<0.001)$, an aspect that has been rarely reported in the past (Table 3 ).

Overall, patients appeared more comfortable with the conscious sedation regimen. In part, this observation may also have been related to the fact that patient positioning for surgery was performed while the patient was lucid, giving feedback on any discomfort arising from the position. Furthermore, lucid patients were familiarized with the surgical surroundings before sedation was deepened. Neither advantage was available with the asleep technique.

Favorable outcomes with fewer complications have been reported for the asleep-awake-asleep technique. ${ }^{9}$ Pain, nausea, respiratory insufficiency, and intraoperative seizures were not significantly more frequent in the asleep group. However, monitoring was terminated because of pain in more patients in the asleep group $(n=4$; Table 2$)$. It has been argued that during opening there is no need for patients to be awake, particularly in surgery for recurrenc- 
es where scar tissue can prolong surgery, which is indeed true. ${ }^{10}$ However, greater compliance, significantly shorter periods of hypertension, shorter postoperative length of stay and shorter duration of surgery, and a reduced need for fluid resuscitation or for premature termination of monitoring (without worse neurological and surgical outcomes) all indicate conscious sedation with dexmedetomidine is superior for awake craniotomies.

\section{Limitations}

A number of limitations from our study merit mention, foremost its retrospective design. However, electronic medical records and digitized anesthesiology protocols helped enormously with the retrospective chart analysis and proved highly reliable. Our detailed analysis of patient characteristics (Table 1) demonstrated no meaningful differences that would question the comparability of the two cohorts. Additionally, compliance was rated using a subjective rating scale from the senior surgeon. Future prospective studies can use validated and more standardized methods to assess these data. This study compared two well-acknowledged anesthesiology settings for awake craniotomies in 1 center, with the same neurosurgical team and under the same type of anesthesiological care. Nevertheless, a prospective, randomized setting would indubitably provide more reliable data to enforce our statements, because differences in a historic comparison might be multifactorial.

\section{Conclusions}

Use of dexmedetomidine creates excellent conditions for awake surgeries. Our experience shows that dexmedetomidine, used as the sole anesthetic drug during awake craniotomies, sedates moderately and acts as an anxiolytic. Thus, after ceasing infusion it enables quick and reliable clinical neurological assessment of patients. It ensures good compliance for neurological monitoring and reduces respiratory and cardiovascular adverse events with a low need for antihypertensive and vasoactive drugs, probably ensuring more rapid surgery and reducing length of hospitalization.

\section{References}

1. Bekker AY, Kaufman B, Samir H, Doyle W: The use of dexmedetomidine infusion for awake craniotomy. Anesth Analg 92:1251-1253, 2001

2. Belleville JP, Ward DS, Bloor BC, Maze M: Effects of intravenous dexmedetomidine in humans. I. Sedation, ventilation, and metabolic rate. Anesthesiology 77:1125-1133, 1992

3. Bhana N, Goa KL, McClellan KJ: Dexmedetomidine. Drugs 59:263-270, 2000

4. Blanshard HJ, Chung F, Manninen PH, Taylor MD, Bernstein M: Awake craniotomy for removal of intracranial tumor: considerations for early discharge. Anesth Analg 92:89-94, 2001

5. Borgeat A: Propofol: pro- or anticonvulsant? Eur J Anaesthesiol Suppl 15:17-20, 1997

6. Candiotti KA, Bergese SD, Bokesch PM, Feldman MA, Wisemandle W, Bekker AY: Monitored anesthesia care with dexmedetomidine: a prospective, randomized, double-blind, multicenter trial. Anesth Analg 110:47-56, 2010

7. Das S, Al-Mashani A, Suri N, Salhotra N, Chatterjee N:
Combination of continuous dexmedetomidine infusion with titrated ultra-low-dose propofol-fentanyl for an awake craniotomy. Sultan Qaboos Univ Med J 16:e347-e351, 2016

8. De Benedictis A, Moritz-Gasser S, Duffau H: Awake mapping optimizes the extent of resection for low-grade gliomas in eloquent areas. Neurosurgery 66:1074-1084, 2010

9. Deras P, Moulinié G, Maldonado IL, Moritz-Gasser S, Duffau H, Bertram L: Intermittent general anesthesia with controlled ventilation for asleep-awake-asleep brain surgery: a prospective series of 140 gliomas in eloquent areas. Neurosurgery 71:764-771, 2012

10. Duffau H: The reliability of asleep-awake-asleep protocol for intraoperative functional mapping and cognitive monitoring in glioma surgery. Acta Neurochir (Wien) 155:1803-1804, 2013

11. Ebert TJ, Hall JE, Barney JA, Uhrich TD, Colinco MD: The effects of increasing plasma concentrations of dexmedetomidine in humans. Anesthesiology 93:382-394, 2000

12. Garavaglia MM, Das S, Cusimano MD, Crescini C, Mazer CD, Hare GM, et al: Anesthetic approach to high-risk patients and prolonged awake craniotomy using dexmedetomidine and scalp block. J Neurosurg Anesthesiol 26:226-233, 2014

13. Goettel N, Bharadwaj S, Venkatraghavan L, Mehta J, Bernstein M, Manninen PH: Dexmedetomidine vs propofol-remifentanil conscious sedation for awake craniotomy: a prospective randomized controlled trial. Br J Anaesth 116:811-821, 2016

14. Hall JE, Uhrich TD, Barney JA, Arain SR, Ebert TJ: Sedative, amnestic, and analgesic properties of small-dose dexmedetomidine infusions. Anesth Analg 90:699-705, 2000

15. Hansen E, Seemann M, Zech N, Doenitz C, Luerding R, Brawanski A: Awake craniotomies without any sedation: the awake-awake-awake technique. Acta Neurochir (Wien) 155:1417-1424, 2013

16. Hill CS, Severgnini F, McKintosh E: How I do it: Awake craniotomy. Acta Neurochir (Wien) 159:173-176, 2017

17. Horsley V: Remarks on ten consecutive cases of operations upon the brain and cranial cavity to illustrate the details and safety of the method employed. BMJ 1:863-865, 1887

18. Jaakola ML, Salonen M, Lehtinen R, Scheinin H: The analgesic action of dexmedetomidine--a novel alpha 2-adrenoceptor agonist--in healthy volunteers. Pain 46:281-285, 1991

19. Nossek E, Matot I, Shahar T, Barzilai O, Rapoport Y, Gonen T, et al: Failed awake craniotomy: a retrospective analysis in 424 patients undergoing craniotomy for brain tumor. J Neurosurg 118:243-249, 2013

20. Nossek E, Matot I, Shahar T, Barzilai O, Rapoport Y, Gonen $\mathrm{T}$, et al: Intraoperative seizures during awake craniotomy: incidence and consequences: analysis of 477 patients. Neurosurgery 73:135-140, 2013

21. Osborn I, Sebeo J: "Scalp block" during craniotomy: a classic technique revisited. J Neurosurg Anesthesiol 22:187-194, 2010

22. Paris A, Tonner PH: Dexmedetomidine in anaesthesia. Curr Opin Anaesthesiol 18:412-418, 2005

23. Peruzzi P, Bergese SD, Viloria A, Puente EG, Abdel-Rasoul M, Chiocca EA: A retrospective cohort-matched comparison of conscious sedation versus general anesthesia for supratentorial glioma resection. Clinical article. J Neurosurg 114:633-639, 2011

24. Rajan S, Cata JP, Nada E, Weil R, Pal R, Avitsian R: Asleepawake-asleep craniotomy: a comparison with general anesthesia for resection of supratentorial tumors. J Clin Neurosci 20:1068-1073, 2013

25. Ramsay MA, Luterman DL: Dexmedetomidine as a total intravenous anesthetic agent. Anesthesiology 101:787-790, 2004

26. Sacko O, Lauwers-Cances V, Brauge D, Sesay M, Brenner A, 
Roux FE: Awake craniotomy vs surgery under general anesthesia for resection of supratentorial lesions. Neurosurgery 68:1192-1199, 2011

27. Sanai N, Mirzadeh Z, Berger MS: Functional outcome after language mapping for glioma resection. $\mathbf{N}$ Engl J Med 358:18-27, 2008

28. Sartorius CJ, Berger MS: Rapid termination of intraoperative stimulation-evoked seizures with application of cold Ringer's lactate to the cortex. Technical note. J Neurosurg 88:349351, 1998

29. Schipmann S, Akalin E, Doods J, Ewelt C, Stummer W, Suero Molina E: When the infection hits the wound: matched case-control study in a neurosurgical patient collective including systematic literature review and risk factors analysis. World Neurosurg 95:178-189, 2016

30. Serletis D, Bernstein M: Prospective study of awake craniotomy used routinely and nonselectively for supratentorial tumors. J Neurosurg 107:1-6, 2007

31. Shen SL, Xie YH, Wang WY, Hu SF, Zhang YL: Comparison of dexmedetomidine and sufentanil for conscious sedation in patients undergoing awake fibreoptic nasotracheal intubation: a prospective, randomised and controlled clinical trial. Clin Respir J 8:100-107, 2014

32. Shen SL, Zheng JY, Zhang J, Wang WY, Jin T, Zhu J, et al: Comparison of dexmedetomidine and propofol for conscious sedation in awake craniotomy: a prospective, double-blind, randomized, and controlled clinical trial. Ann Pharmacother 47:1391-1399, 2013

33. Sheshadri V, Chandramouli BA: Pediatric awake craniotomy for seizure focus resection with dexmedetomidine sedation-a case report. J Clin Anesth 32:199-202, 2016

34. Souter MJ, Rozet I, Ojemann JG, Souter KJ, Holmes MD, Lee L, et al: Dexmedetomidine sedation during awake craniotomy for seizure resection: effects on electrocorticography. J Neurosurg Anesthesiol 19:38-44, 2007

35. Stevanovic A, Rossaint R, Veldeman M, Bilotta F, Coburn M: Anaesthesia management for awake craniotomy: systematic review and meta-analysis. PLoS One 11:e0156448, 2016

36. Szelényi A, Bello L, Duffau H, Fava E, Feigl GC, Galanda
M, et al: Intraoperative electrical stimulation in awake craniotomy: methodological aspects of current practice. Neurosurg Focus 28(2):E7, 2010

37. Taylor MD, Bernstein M: Awake craniotomy with brain mapping as the routine surgical approach to treating patients with supratentorial intraaxial tumors: a prospective trial of 200 cases. J Neurosurg 90:35-41, 1999

38. Uyar AS, Yagmurdur H, Fidan Y, Topkaya C, Basar H: Dexmedetomidine attenuates the hemodynamic and neuroendocrinal responses to skull-pin head-holder application during craniotomy. J Neurosurg Anesthesiol 20:174-179, 2008

\section{Disclosures}

The authors report no conflict of interest concerning the materials or methods used in this study or the findings specified in this paper.

\section{Author Contributions}

Conception and design: Suero Molina, Schipmann, Maas, Stummer. Acquisition of data: Suero Molina, Schipmann, Mueller. Analysis and interpretation of data: Suero Molina, Schipmann, Mueller, Maas, Brokinkel, Stummer. Drafting the article: Suero Molina, Schipmann. Critically revising the article: Suero Molina, Schipmann, Maas, Wölfer, Ewelt, Brokinkel, Stummer. Reviewed submitted version of manuscript: Suero Molina, Schipmann, Maas, Wölfer, Ewelt, Brokinkel, Stummer. Approved the final version of the manuscript on behalf of all authors: Suero Molina. Statistical analysis: Suero Molina, Schipmann, Mueller, Stummer. Administrative/technical/material support: Suero Molina, Schipmann, Maas, Wölfer, Ewelt, Stummer. Study supervision: Suero Molina, Schipmann, Stummer.

\section{Correspondence}

Eric Suero Molina: University Hospital of Münster, Germany. eric.suero@ukmuenster.de. 